\title{
Elucidation of CRISPR-Cas9 Application in Novel Cellular Immunotherapy.
}

\author{
Sameer Quazi, \\ Founder \& CEO, GenLab Biosolutions Private Limited, Bangalore, Karnataka, India. 560043 \\ Colonel.quazi@gmail.com
}

\begin{abstract}
:
Novel Cellular Immunotherapy with engineered $\mathrm{T}$ cells has improved cancer treatment and established therapeutic promises to prevent tumor formation in clinical studies. Due to certain restrictions and difficulties, CAR and TCR T cells therapies were inadequate at points. CRISPR Cas9 genome-editing tool has a significant potential for these two cell-based therapies. As a specialized gene-editing technique, CRISPR Cas9 is used to repair genetic alternation with minimum damage. It is used as an adjunct to Immunotherapy to stimulate a more robust immune response. CRISPR has long outpaced other target-specific genome editing methods such as ZFNs and TALEN due to its high efficiency, competence in targeting, and stable operating condition. CRISPR can overcome the two major drawbacks of universal CAR T cells: allorejection and graft-vs-host disease. TCR-based $\mathrm{T}$ cell treatment can reduce inappropriate binding between endogenous and transgenic TCR, resulting in a reduction of severe toxicity. The CAR and TCR T based cell therapies uphold an excellent future for tumor malignancies

This article has elucidated the administration of CRISPR Cas9 in Novel Cellular Immunotherapy, CAR, and TCR T cell therapy. However, this article did not fail to observe this technology's ethical concerns, limitations, and challenges. Furthermore, the article compares CRISPR-mediated allogeneic CAR T cell to TCR-T cell therapy.
\end{abstract}

Keywords: CAR T cell, ZFNs, TALEN, TCR T cell, CRISPR Cas9, Alloreactivity, GHVD. 


\section{Introduction}

Cancer is known as one of the most lethal diseases in the world. Following cardiovascular disease, it is the second leading cause of mortality. [1]. Carcinogenesis can trigger by genetic diversity in an individual's DNA, which induces a complicated immunological response. It encompasses both tumor cells' immune evasion and the tumor microenvironment's immunosuppressive nature. [2]. Recently, scientists have used various genetic manipulation techniques to repair the DNA in the genome of a cell via site-specific modification. These techniques can edit tumor cell's genomes to meet apoptosis, decrease the drug resistance and replace mutant genes [3-6]. Aside from traditional cancer treatments like chemotherapy, radiation, and surgery, newer approaches like oncolytic virotherapy developed to use the immune system against cancer cells. $[7,8]$.

Immunotherapy, including checkpoint inhibitors and adoptive $\mathrm{T}$ cell therapy, has been very successful in treating different malignancies. It functions by reversing the tumor-initiated immunosuppression and boosting immunity against cancers [9]. Anti-programmed death 1 (PD-1/PDL-1) and cytotoxic T-Lymphocyte Associated Protein 4 (CTLA-1) are immune checkpoint inhibitors that play a significant role in blocking immunosuppressive signals promoting $\mathrm{T}$ cell renewal. In comparison, ACT or adoptive cell transfer could be accomplished through distinct immunogenic processes such TILs, engineered CAR T, and TCR T cells [11]. Recent development in molecular biology has led to the advancement and refinement of gene editing technologies. A gene-engineering tool is required to achieve the desired outcome in novel cellular Immunotherapy, particularly in CARs and TCR T cells.

Clustered regularly interspaced short palindromic repeats associated with Cas protein nine is defined as CRISPR Cas9. It outperforms alternative gene engineering tools, ZFNs and TALENs, over its straightforwardness, high accuracy, and multiple gene targeting capabilities [12]. It is a sophisticated technique for gene editing that has been using in cancer research.

Researchers have used CRISPR technology to design cancer models, identify novel immunotherapy targets, potentially accredit genes for drug trials, examine individuals' drug resistance mechanisms, and gain a brief understanding of the mode of action of non-coding gene regions, among other applications [13-20]. CRISPR may be used to treat tumors using cancer immunotherapy by enhancing efficiency and safety. The application of CRISPR Cas9 with cancer immunotherapy has a great potential to revolutionize cancer treatment by alleviating patients' suffering from untargeted therapies like chemotherapy and radiation. 


\section{CARs- Tcell Immunotherapy through CRISPR Cas9 system}

CARs (chimeric antigen receptors) were initially developed in 1989 [21]. Over the last few decades, engineered T cells with CARs have shown significant effectiveness in the treatment of various types of leukemia. [22]. Chimeric antigen receptors are composed of three components: A ScFv derived from a monoclonal antibody, an extracellular antigen-recognition site, a hydrophobic domain, and intracellular signaling transduction, which contains a CD3 chain with costimulatory molecules such as CD137, CD28, OX40 4-1-BB, CD3ל, (Figure 1). According to their endodomain structure, CAR $\mathrm{T}$ cells can divide into four generations.

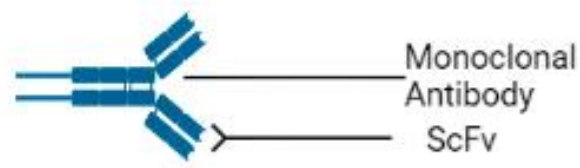

Antigen Binding Region

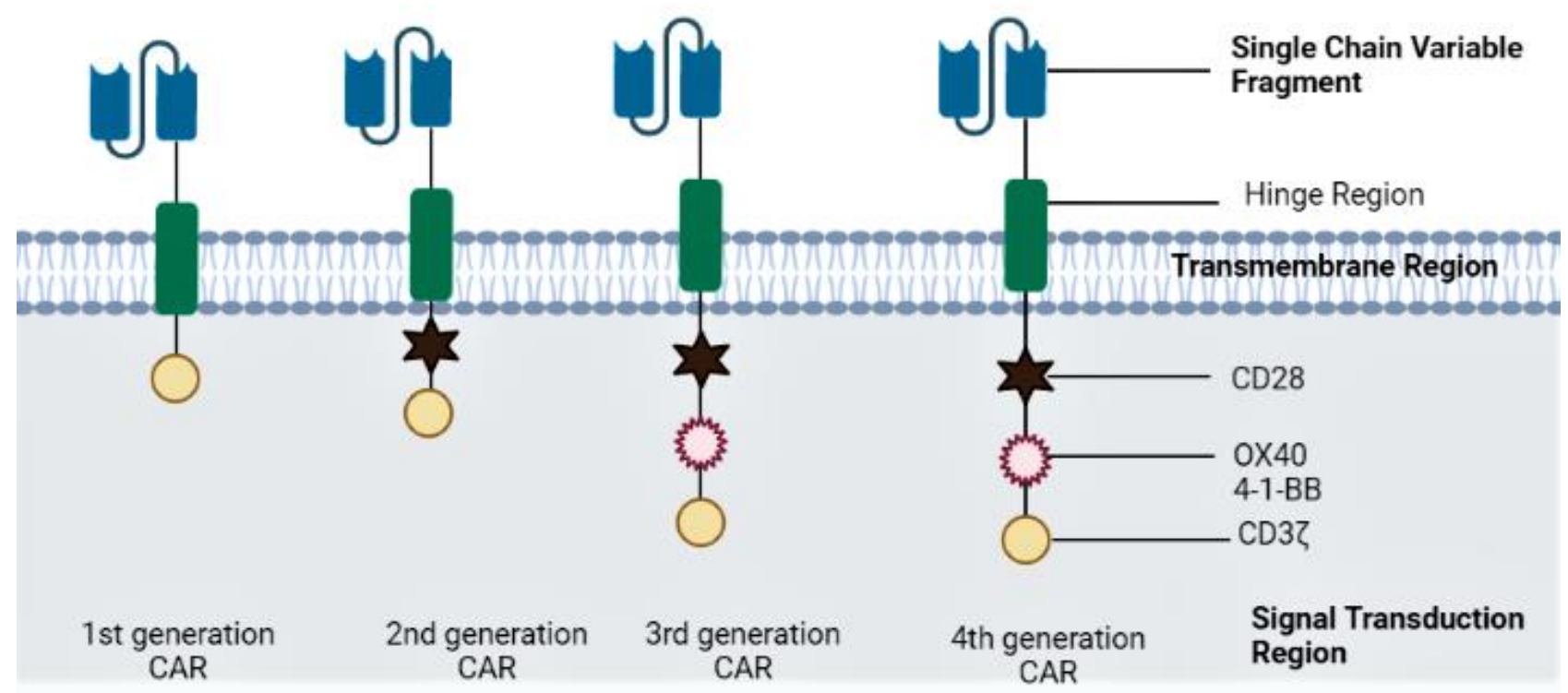

Figure 1: A schematic illustration of Chimeric Antigen Receptor from $1^{\text {st }}$ Generation to $4^{\text {th }}$ Generation. 
The discovery of genetically modified CAR $\mathrm{T}$ cells has unfolded a new revolutionary era in cancer treatment. [21,23,24]. Kymriah and Yescarta were the initial CAR T cell therapy authorized by the US Food and Drug Administration after their successful impact on B cell malignancies. [25]. The two CD19-directed CAR-T cell therapies were authorized to treat B lymphoblastic leukemia in adolescents and large B cell lymphoma in adults. The FDA authorized two more CAR-T cell treatments, Tecartus and Breyanzi, in 2020 and 2021, respectively, to treat mantle cell lymphoma (MCL) and highly resistant large B cell lymphoma. While the success rate of this treatment was rising, many patients were unable to get it for various reasons. As laborious and costly, patients with advanced level diseases could not make the grade to Immunotherapy. The second instance was the production of the finest quality of $\mathrm{T}$ cells from individuals with lymphopenia. [26]. Compared to individuals' CAR-T cells, allorejection and GVHD (graft versus host disease) were the primary concerns with allogeneic CAR-T cells, caused by pre-existent endogenous TCR and HLA I on donor's T cells. CRISPR technology has outperformed the previous genome modifying technologies in terms of efficiency and versatility in the production of CAR-T cells.

Researches have demonstrated that using multiple guided RNAs inserted in a CAR lentiviral vector allows CRISPR to knock off gene loci such as TCR/TCR class 1, PD-1, HLA class1, Fas, in one shot [28,29]. Ren et al. published another study in 2017 demonstrating that utilizing CRISPR to initiate CAR-T cells production can decrease endogenous TCR, MHC I corresponded HLA I, and PD1, thus increasing anti-cancer immunity in clinical investigations [30].

Immune checkpoint inhibition is another exciting therapeutic therapy option for a variety of malignancies. Immune checkpoint regulators including PD-1,(CTLA-4),LAG3,TIM-3, HAVCR2, 2B4 (CD244), CD160, and TIGIT have revolutionized immunotherapy [31,32].

Upregulation of these immune checkpoint regulators and their ligands may include dysfunctional CARs $\mathrm{T}$ cell activity [33]. Researchers have conducted numerous studies to overcome these obstacles.

Finally, the CRISPR-mediated knockout system for these checkpoint inhibitors has demonstrated no evidence of alloreactivity. Consequently, it enhanced CAR T cell functional activity and opened the path for universal CAR T cell development from healthy donors. 
Table 1: CRISPR Cas9 mediated inhibition of Immnune Check Regulators from CAR T cell

\begin{tabular}{|c|c|c|c|}
\hline $\begin{array}{l}\text { Targeted } \\
\text { Gene }\end{array}$ & $\begin{array}{c}\text { Types of Cancer/Cancer } \\
\text { Cell lines }\end{array}$ & Results & References \\
\hline PD1 & $\begin{array}{l}\text { Glioblastoma (GBM) } \\
\text { hepatocellular carcinoma } \\
\text { Cell lines:K562 tumor, } \\
\text { non small lung cancer( in } \\
\text { clinical trial) }\end{array}$ & $\begin{array}{l}\text { In Car T cells, disrupting PD-1 enhances anti-tumor } \\
\text { activity, decreases exhaustion, and improves killing } \\
\text { power. }\end{array}$ & [34-36] \\
\hline LAG 3 & Cell lines: K19, K562 & $\begin{array}{l}\text { LAG3 gene knockout the CARs } \mathrm{T} \text { cells display } \\
\text { comparable function to the standard CARs } \mathrm{T} \text { cell. }\end{array}$ & [37] \\
\hline GM CSF & NALM6 & $\begin{array}{l}\text { Increases tumor killing activity and survivance of } \\
\mathrm{CAR} \mathrm{T} \text { cell and also reduces neuro-inflammation } \\
\text { and chances of CRS. }\end{array}$ & [38] \\
\hline $\begin{array}{l}\text { CD7 and } \\
\text { TRAC }\end{array}$ & $\begin{array}{l}\text { T cell lymphoblastic } \\
\text { leukemia }\end{array}$ & $\begin{array}{l}\text { Knocking out CD7 and TRAC gene from CARs T cell } \\
\text { increase the efficiency of the treatment. }\end{array}$ & [39] \\
\hline DGK & $\begin{array}{l}\text { U87 MG } \\
\text { glioblastoma cell line }\end{array}$ & $\begin{array}{l}\text { DGK gene knockout increases CD3 signaling and } \\
\text { re-boots TCR signaling. }\end{array}$ & [40] \\
\hline TGFBR2 & $\begin{array}{l}\text { Anti mesothelin CARs } \mathrm{T} \\
\text { cell }\end{array}$ & $\begin{array}{l}\text { TGFBR2 gene deletion in CAR } \mathrm{T} \text { cells improves } \\
\text { tumor cell eradication while simultaneously increasing } \\
\text { memory cell production. }\end{array}$ & [41] \\
\hline CTLA4 & Bladder cancer & $\begin{array}{l}\text { In an in vitro study, CTLA-4 disruption improves } \\
\text { cells' immune response and damage inpatient with } \\
\text { CD80/CD86-positive bladder cancer. }\end{array}$ & [42] \\
\hline
\end{tabular}

PD1-programmed death-1, CD7-Cluster of Differentiation 7, GM CSF- granulocyte-macrophage colony-stimulating factor, TGFBR2-TGF- $\beta$ receptor II, LAG 3- lymphocyte activation gene 3 protein, , DGK-Diacylglycerol Kinase, CTLA- 4-Cytotoxic T Lymphocyte Protein 4, TRAC-T Cell Receptor Alpha Constant 
Several researchers have employed CRISPR Cas9 to disrupt the PD-1 gene from CAR T cells in primary brain cancer, hepatocellular carcinoma, and K562 tumor cell lines. The Programmed death one removal from CAR T cells increased the tumor-killing activity. It also reduced exhaustion and improved the cancer-killing ability of $\mathrm{T}$ cells [34-36]. The application of CRISPR technology to remove additional genes from CAR T cells, including LAG 3, GM CSF, CD7, TRAC, DGK, and CTLA-4, showed remarkable improvement in CAR T cell performance.

\section{TCR based T cell Immunotherapy by CRISPR Cas9:}

Engineered TCR T cell immunotherapy upholds a higher affinity in targeting a wide range of antigens in numerous cancers. It has shown significant curative promises in multiple cancer, along with melanoma [43,44], sarcoma [43], and multiple myeloma [45]. Antigen-recognition receptors present on the surface of $\mathrm{T}$ cells are known as $\mathrm{T}$ cell receptors. $\mathrm{T}$ cell receptors are heterodimers that contain two chains: $\alpha$ chain and $\beta$ chain. The $\alpha$ chains and $\beta$ chains include a variable antigen-binding region, an extracellular area, and a hydrophobic domain. The complex formed between TCR and CD3 is called TCR/CD3 complex. It is composed of TCR/ and CD3 chains with $\gamma, \delta, \zeta, \varepsilon$. (Figure 2). Through an MHC recognition pattern, this TCR/CD3 complex may identify tumor-specific antigens. 


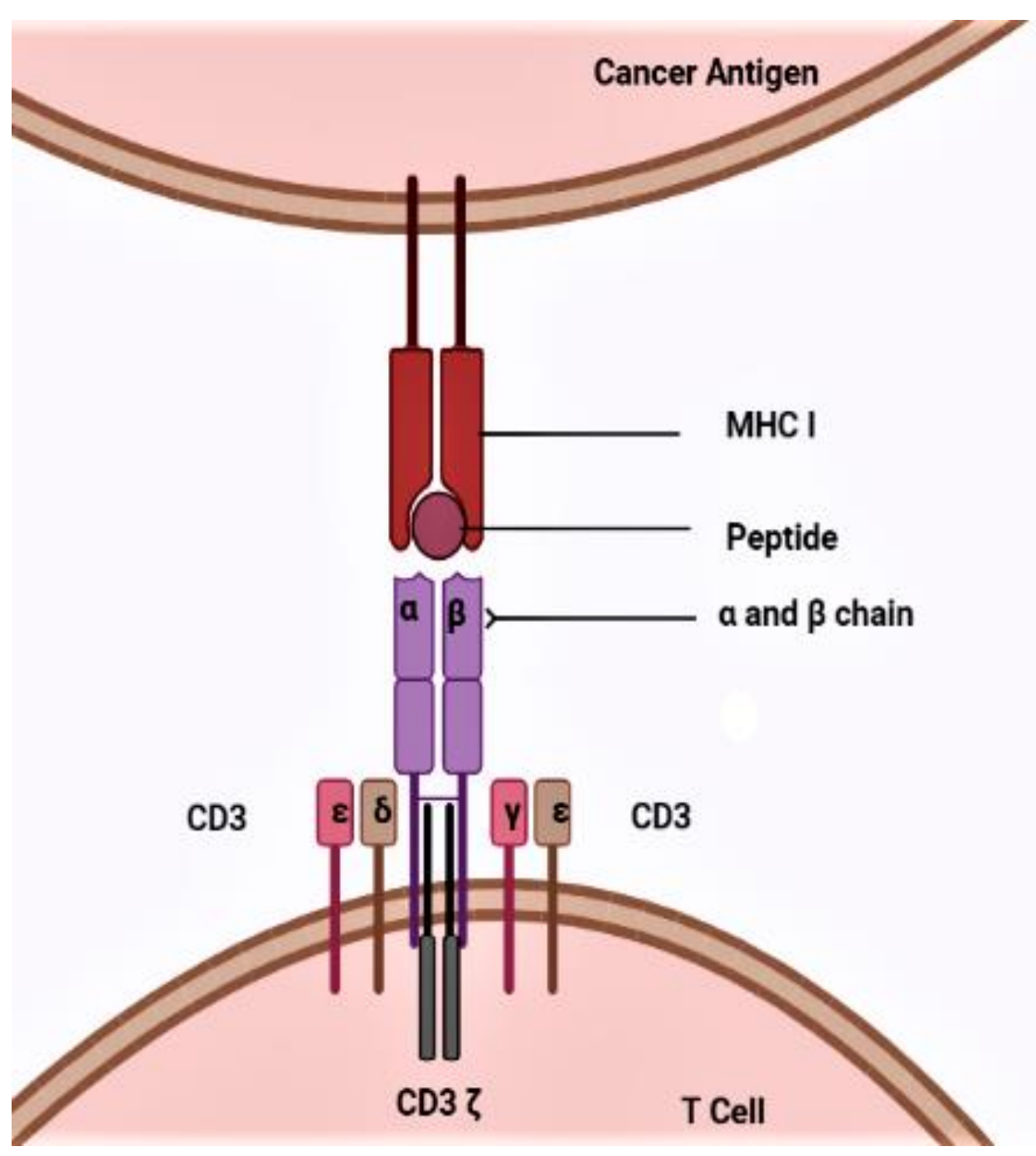

Figure 2: A structural overview of TCR /CD3 complex detecting cancer tumor antigen.

Genetically modified TCRs' are inserted in the recipient T cells through retroviral gene transfer [46]. Due to pre-existent endogenous TCR, the recombinant TCR engages in a competition to form CD3 and cell surface expression. Therefore, the mispairing between the recombinant and endogenous TCRs forms a mixed dimer, resulting in dilution of the surface expression and detrimental autoreactivity [47,48]. Endogenous TCRs' have low efficiency in targeting self-antigens on normal cell-like TAAs (tumor-associated antigens) than foreign invaders like bacteria and viruses [49]. Thus, treating cancer with natural TCRs has delayed the treatment progression because cancer-specific antigens are also like TAAs on normal cells. In 2006, a study carried out by Morgan et al. performed a clinical experiment to treat patients with melanoma. He targeted melanocyte differentiation antigen (Mart1) using natural TCRs with different levels of targeting efficiency. The study uncovered that DMF4 (low-affinity of $\mathrm{T}$ cells) was well tolerated but lacked anti-tumor 
efficacy. He then used DMF5 (higher affinity of T cells) in the research. The result indicated an increased degree of anti-tumor efficacy and significant toxicity [50].

To overcome this limitation barrier, CRISPR Cas9 was employed with a manufactured tumor-specific TCR sequence to disrupt the $\alpha$ and $\beta$ genes present on the endogenous TCRs $[45,51,52]$. Legut et al. reported that replacing endogenous TCRs from $\mathrm{T}$ cells upgrades surface expression and transgenic TCR T cells [52]. Researchers adopted another technique to reduce the inappropriate pairing between the endogenous and engineered TCRs. CRISPR Cas9 was used with the transduction of a stabilized single-chain TCRs to disrupt the mispairing, which showed promising results [53].

In 2020, the first clinical study of CRISPR mediated T cell therapy w applied to cancer patients who were not responding to previous treatment [54]. By using the lentiviral transduction process, the autologous T cells from patients were modified. Later on, CRISPR disrupted the endogenous TCR and PD1. Then the modified TCR Tcells therapy was applied to three patients where two of them showed stable results; then another showed disease advancement [54]

CRISPR Cas9 mediated transgenic cell receptor $\mathrm{T}$ cell therapy may bring unprecedented results in cancer remission in the upcoming future by eradicating the limitations and challenges

\section{CRISPR-mediated CAR T cell therapy over TCR T cell therapy: Present and Future}

Chimeric Antigen Receptor- $\mathrm{T}$ cells could detect peptide antigens and effectively identify carbohydrates and glycolipid antigens, allowing for a broad spectrum of the target of cancer antigens [55]. When CARs T cells were compared to TILs and TCR-T cell therapy, CARs T cells were more effective on many criteria, including lower cell therapy dosages, increased specificity, a clear target for selecting cancer-specific antigens, and a small number of single transfusion cells used in the treatment [55]. CAR T cell immunotherapy has demonstrated promising outcomes in hematological malignancies. Still, regarding solid tumors, it has a minor impact due to the absence of specific antigens for tumors, antigen heterogeneity, and tumor microenvironment. Additionally, threatening adverse events including cytokine release syndrome (CRS), neuroinflammation, and difficulties associated with alloreactivity, GVHD, and overexpression of immune checkpoint inhibitors during manufacturing of universal CAR T cells made this therapy less effective than TCR- T cell therapy.

$\mathrm{T}$ cells based on transgenic cell receptors could detect antigens generated by MHC molecules, regardless of whether they were intracellular, cell surface, or neo-antigens. The intracellular 
antigens recognition by TCR-T cells produced a broad range in targeting antigens [55]. Therefore, researchers used various methods of TCR-Tcell therapy in hematological and solid tumors, which have positive outcomes in cancer treatment. As TCR-T cells treatment is MHC-centered, there is always a risk of mispairing between endogenous and transgenic TCR. Consequently, such mispairing between two TCRs may lead to significant toxicity, inducing GVHD in patients. Adjusting affinity levels was another issue in this cell treatment because a greater affinity level may provide misleading findings, while lower affinity reduces the anti-tumor effectiveness. Though TCR-T cells-based immunotherapy had demonstrated promising therapeutic benefits on cancer treatment, the constraints made it tough to co-operate in clinical trials.

Until recently, experts have tried a variety of methods to cure cancer fully. Immunotherapy has changed the scenario in the fight against cancer treatment. Lately, the US Food and Drug Administration has approved a variety of immunotherapies against carcinomas. Despite this, new cellular immunotherapies based on CAR and TCR T cells have a more significant effect on therapy. Researchers have used CRISPR Cas9 genome editing to address the challenges of these two T cell-based immunotherapies.

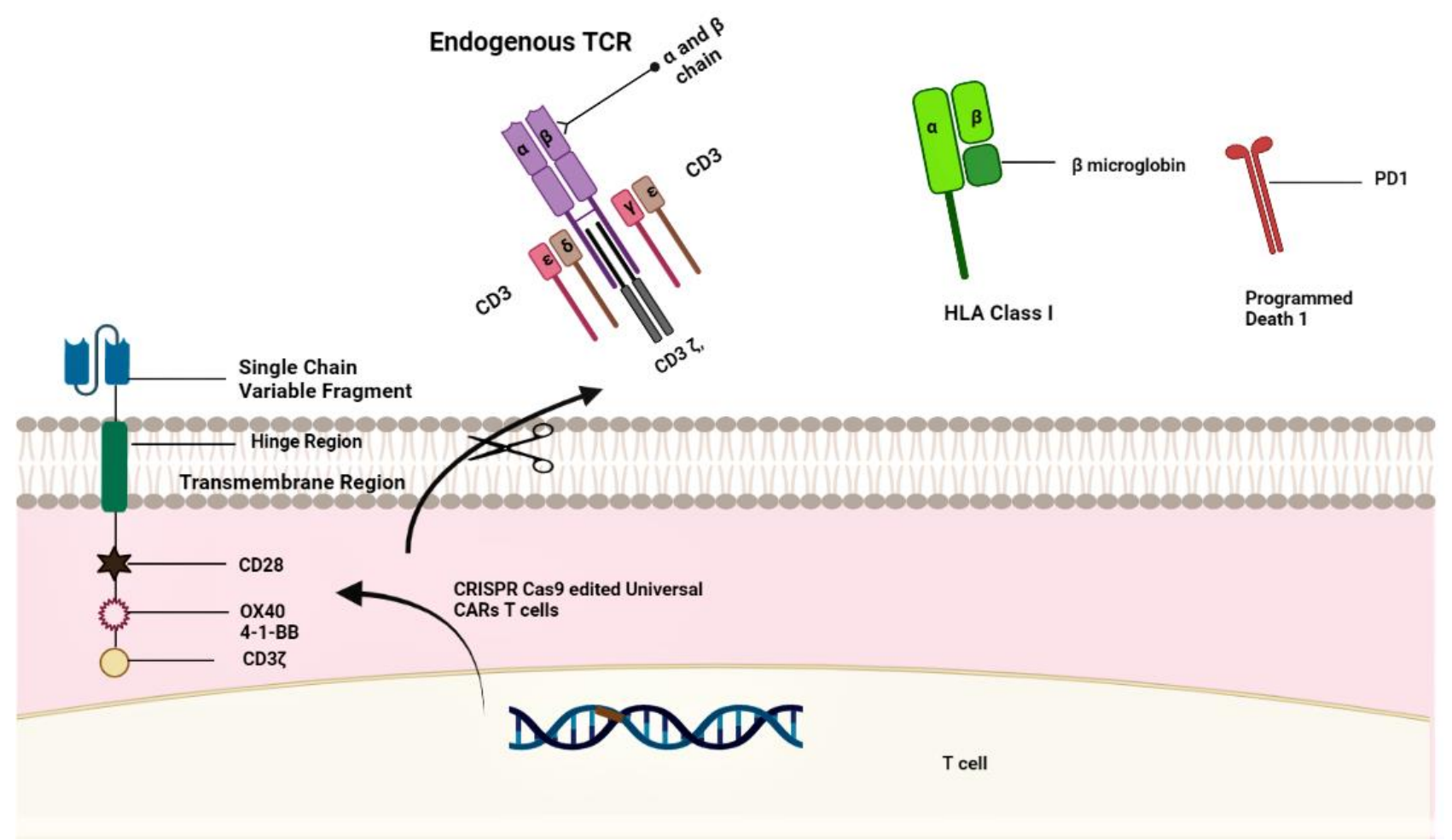

Figure 3: An illustration of CRISPR Cas9 mediated CAR T cell : Disruption of endogenous TCR, HLA Class I and PD1 
We already know that the pre-existent endogenous HLA and TCR on donor T cells may result in alloreactivity and GVHD during CAR T cell generation. Numerous groups believe that the primary cause of GVHD is the $\alpha \beta$ chain on T cells used in developing CAR T cells [56]. In recent years, significant advancements in gene-editing technology have given the tools required to suppress endogenous TCR expression and reduce GVHD risk.

Using CRISPR/Cas9, several groups are eradicating TCR expression on the T cell surface by genetically deleting exons from the TRAC and TRBC1 or 2 (TRBC2) locus [57,58]. CRISPR/Cas9 mediated universal CAR T cells can disrupt TCR and MHC class I [28], Fas, or PD1/CTLA4 (Figure3) [30]. Multiple gene editing may help reduce alloreactivity while also boosting apoptosis and immunosuppressive resistance.

Furthermore, it increases the risk of off-target cleavage, leading to more significant CAR T cell proliferation when tumor suppressor genes are lost $[59,60]$. One of the unique methods for obtaining functional benefits and avoiding GVHD in a more regulated manner is using CRISPR to directly insert the chimeric antigen receptor transgene into the $\mathrm{T}$ Cell Receptor Alpha Constant. Moreover, to GVHD, this modification enables the CAR to be expressed homogeneously and controlled under the TCR promoter, a characteristic that has reduced differentiation and exhaustion [57, 61,62,63]. Additionally, CRISPR was capable of mitigating the adverse effects of this treatment. In clinical trials, Sterner et al. showed that CRISPR could disrupt the granulocyte-macrophage colony-stimulating factor gene, improving $\mathrm{T}$ cells anti-tumor activity while also lowering the chances of cytokine release syndrome and neuroinflammation. (Table 1) [38]. Tang et al. found that using CRISPR technology to disrupt the endogenous TGF- receptor II (TGFBR2) reduces CART cell fatigue and improves tumor-killing efficacy. [41] Such changes in CAR T cells therapy after CRISPR modification have led researchers to apply it clinically. Several clinical studies on CRISPR Cas9-mediated CAR T cells are currently ongoing.

According to Clinical.gov, eight clinical studies are actively enrolling participants for this modified $\mathrm{T}$ cell therapy. 
Table 2: Currently Recruiting Clinical Trials for CRISPR Cas9 mediated CARs T cell therapy

\begin{tabular}{|c|c|c|c|c|c|c|}
\hline $\begin{array}{l}\text { ClinicalTrials. } \\
\text { gov Identifier }\end{array}$ & Conditions & Phase & Target Genes & Treatment & $\begin{array}{l}\text { Estimated } \\
\text { Enrollment }\end{array}$ & Trial Sites \\
\hline NCT03545815 & Adult solid tumor & I & PD1, TCR & Anti-mesothelin CAR-T cells & 10 participants & China \\
\hline NCT03166878 & $\begin{array}{l}\text { Leukemia / } \\
\text { Lymphoma on B } \\
\text { cell }\end{array}$ & I , II & $\begin{array}{l}\text { TCR and B2M } \\
\text { genes }\end{array}$ & UCART019 & 80 participants & China \\
\hline NCT03398967 & $\begin{array}{l}\text { B cell } \\
\text { leukemia/Lymph } \\
\text { oma }\end{array}$ & $\overline{\mathrm{I}, \mathrm{II}}$ & Unknown & $\begin{array}{l}\text { CD19,CD20 / CD22 CAR-T } \\
\text { cells }\end{array}$ & 80 participants & China \\
\hline NCT04502446 & $\begin{array}{l}\text { T Cell } \\
\text { Lymphoma }\end{array}$ & I & Unknown & CTX130 & 45 Participants & $\begin{array}{l}\text { USA, } \\
\text { Canada,Austra } \\
\text { lia }\end{array}$ \\
\hline NCT04244656 & $\begin{array}{l}\text { Multiple } \\
\text { Myeloma }\end{array}$ & I & Unknown & $\begin{array}{l}\text { CTX120-(BCMA)-directed } \\
\text { CAR T-cell immunotherapy }\end{array}$ & 80 Participants & $\begin{array}{l}\text { USA,Australia, } \\
\text { Canada, Spain }\end{array}$ \\
\hline NCT04438083 & $\begin{array}{l}\text { Renal } \\
\text { Carcinoma }\end{array}$ & I & Unknown & CTX130 & 107 Participants & $\begin{array}{l}\text { USA,Canada, } \\
\text { Australia, } \\
\text { Netherlands }\end{array}$ \\
\hline NCT04637763 & $\begin{array}{l}\text { Non-Hodgkin's } \\
\text { Lymphoma }\end{array}$ & I & Unknown & $\begin{array}{l}\text { CB-010 } \\
\text { Drug: Cyclophosphamide Drug: } \\
\text { Fludarabine }\end{array}$ & 50 participants & USA \\
\hline NCT04035434 & $\begin{array}{l}\text { Malignant } \\
\text { Non-Hodgkin's } \\
\text { Lymphoma }\end{array}$ & I & Unknown & CTX110 & 143 Participants & $\begin{array}{l}\text { USA, } \\
\text { Australia,Cana } \\
\text { da,Germany }\end{array}$ \\
\hline
\end{tabular}

Accessed From : ClinicalTrials.gov 
On the other hand, CRISPR Cas9 application in TCR T cell treatment has demonstrated promising outcomes in decreasing undesirable effects associated with prior TCR T cell therapy.

The first clinical trial performed by Stadtmauer et al., using CRISPR-mediated TCR T cell treatment, demonstrated that it has a bright future but requires further investigation. [54]. Before applying CRISPR, TCR-T cell treatment was preferable because of its capacity to target a wide variety of tumor antigens. However, the scenario has reversed by the development of the CRISPR Cas9. CRISPR-mediated universal CAR T cell immunotherapy can target solid and hematological malignancies by CRISPRs' diverse gene targeting capability. As a result, universal CAR-T cell-based Immunotherapy engineered by CRISPR may reign in a revolution in the coming years. 


\section{Conclusion}

Humanity has overcome complex challenges in the past and emerged victorious [64]. However, humankind is engulfed in darkness, with no apparent cures for illnesses such as cancer and HIV. Scientists have worked effortlessly to find a natural remedy for cancer. Though chemotherapy and radiation may kill all cancer cells and prevent the illness from returning, individuals with suppressed immunity found it challenging to cope with the disease's retreat and adverse effects. In recent years, Immunotherapy has been well known for its contribution to vital cancer. Immunotherapy works by reinforcing the immune system's ability to identify and destroy tumor antigens. Since the early decades, drugs development and repurposing have had a long and complicated history. The discovery of a new drug remains a lengthy process, requiring approximately ten to twelve years to bring effective medicine or potential drug molecule from the laboratory to the marketplace [65]. It reported that the average cost of getting medication to market is more than 3 billion dollars [66]. Several companies worldwide have been advancing their ideas to the clinical stage. Therefore, CAR-T cell treatments for various cancers are anticipated to be available in the future [55]. The third and fourth generations of CRISPR Cas9 mediated CARs T cell therapy have shown higher efficiency and specificity in clinical trials, opening a new door for the transformation of the treatment of various blood cancers and solid tumors[67]. On the other side, CRISPR-mediated TCR-T treatments can be more beneficial for solid cancers. The goal of these two therapies is to increase their specificity and efficiency and decrease the adverse effects of cancer treatment. This purpose may be achieved by using CRISPR gene editing as a tool for gene therapy, identifying particular tumor antigens, and enhancing cellular immunotherapies; however, any limits and concerns should be considered before proceeding with any clinical trials. 
1. Cooper, G. M., \& Hausman, R. E. (2000). The development and causes of cancer. The cell: A molecular approach,

2. Zindl, C. L., \& Chaplin, D. D. (2010). Tumor immune evasion. Science, 328(5979), 697-698.

3. Amer, M. H. (2014). Gene therapy for cancer: present status and future perspective. Molecular and cellular therapies, 2(1), 1-19.

4. Chira, S., Gulei, D., Hajitou, A., \& Berindan-Neagoe, I. (2018). Restoring the p53 'Guardian'phenotype in p53-deficient tumor cells with CRISPR/Cas9. Trends in biotechnology, 36(7), 653-660.

5. Maeder, M. L., \& Gersbach, C. A. (2016). Genome-editing technologies for gene and cell therapy. Molecular Therapy, 24(3), 430-446.

6. Yin, H., Xue, W., \& Anderson, D. G. (2019). CRISPR-Cas: a tool for cancer research and therapeutics. Nature Reviews Clinical Oncology, 16(5), 281-295.

7. Sun, L., Chen, L., \& Li, H. (2019). Checkpoint-modulating immunotherapies in tumor treatment: Targets, drugs, and mechanisms. International immunopharmacology, 67, 160-175.

8. Keshavarz, M., Solaymani-Mohammadi, F., Miri, S. M., \& Ghaemi, A. (2019). Oncolytic paramyxoviruses-induced autophagy; a prudent weapon for cancer therapy. Journal of biomedical science, 26(1), 1-11.

9. O’Donnell, J. S., Teng, M. W., \& Smyth, M. J. (2019). Cancer immunoediting and resistance to T cell-based immunotherapy. Nature reviews Clinical oncology, 16(3), 151-167.

10. Azangou-Khyavy, M., Ghasemi, M., Khanali, J., Boroomand-Saboor, M., Jamalkhah, M., Soleimani, M., \& Kiani, J. (2020). CRISPR/Cas: From tumor gene editing to T cell-based immunotherapy of cancer. Frontiers in Immunology.

11. Bommareddy, P. K., Shettigar, M., \& Kaufman, H. L. (2018). Integrating oncolytic viruses in combination cancer immunotherapy. Nature Reviews Immunology, 18(8), 498-513.

12. Huang, C. H., Lee, K. C., \& Doudna, J. A. (2018). Applications of CRISPR-Cas enzymes in cancer therapeutics and detection. Trends in cancer, 4(7), 499-512.

13. Platt, R. J., Chen, S., Zhou, Y., Yim, M. J., Swiech, L., Kempton, H. R., ... \& Heidenreich, M. (2014). Xavier 45 RJ, Langer R, Anderson DG, Hacohen N, Regev A, Feng G, Sharp PA, Zhang F. CRISPR-Cas9 knockin mice for genome editing and cancer modeling. Cell, 159, 440-55.

14. Tuveson, D., \& Clevers, H. (2019). Cancer modeling meets human organoid technology. Science, 364(6444), 952-955.

15. Evers, B., Jastrzebski, K., Heijmans, J. P., Grernrum, W., Beijersbergen, R. L., \& Bernards, R. (2016). CRISPR knockout screening outperforms shRNA and CRISPRi in identifying essential genes. Nature biotechnology, 34(6), 631-633.

16. Vickers, N. J. (2017). Animal communication: when i'm calling you, will you answer too?. Current biology, 27(14), R713-R715.

17. Pettitt, S. J., Krastev, D. B., Brandsma, I., Dréan, A., Song, F., Aleksandrov, R., ... \& Lord, C. J. (2018). Genome-wide and high-density CRISPR-Cas9 screens identify point mutations in PARP1 causing PARP inhibitor resistance. Nature communications, 9(1), 1-14. 
18. Wei, L., Lee, D., Law, C. T., Zhang, M. S., Shen, J., Chin, D. W. C., ... \& Wong, C. M. (2019). Genome-wide CRISPR/Cas9 library screening identified PHGDH as a critical driver for Sorafenib resistance in HCC. Nature communications, 10(1), 1-13.

19. Zhu, S., Li, W., Liu, J., Chen, C. H., Liao, Q., Xu, P., ... \& Wei, W. (2016). Genome-scale deletion screening of human long non-coding RNAs using a paired-guide RNA CRISPRCas9 library. Nature biotechnology, 34(12), 1279-1286.

20. Esposito, Roberta, Núria Bosch, Andrés Lanzós, Taisia Polidori, Carlos Pulido-Quetglas, and Rory Johnson. "Hacking the cancer genome: profiling therapeutically actionable long non-coding RNAs using CRISPR-Cas9 screening." Cancer cell 35, no. 4 (2019): 545-557.

21. Zhang, C., Liu, J., Zhong, J. F., \& Zhang, X. (2017). Engineering car-t cells. Biomarker research, 5(1), 1-6.

22. June, C. H., \& Sadelain, M. (2018). Chimeric antigen receptor therapy. New England Journal of Medicine, 379(1), 64-73.

23. Jackson, H. J., Rafiq, S., \& Brentjens, R. J. (2016). Driving CAR T-cells forward. Nature reviews Clinical oncology, 13(6), 370-383.

24. Labanieh, L., Majzner, R. G., \& Mackall, C. L. (2018). Programming CAR-T cells to kill cancer. Nature biomedical engineering, 2(6), 377-391.

25. Maude, S. L., Frey, N., Shaw, P. A., Aplenc, R., Barrett, D. M., Bunin, N. J., ... \& Grupp, S. A. (2014). Chimeric antigen receptor $\mathrm{T}$ cells for sustained remissions in leukemia. New England Journal of Medicine, 371(16), 1507-1517.

26. Torikai, H., \& Cooper, L. J. (2016). Translational implications for off-the-shelf immune cells expressing chimeric antigen receptors. Molecular Therapy, 24(7), 1178-1186.

27. Depil, S., Duchateau, P., Grupp, S. A., Mufti, G., \& Poirot, L. (2020). 'Off-the-shelf'allogeneic CAR T cells: development and challenges. Nature reviews Drug discovery, 19(3), 185-199.

28. Ren, J., Zhang, X., Liu, X., Fang, C., Jiang, S., June, C. H., \& Zhao, Y. (2017). A versatile system for rapid multiplex genome-edited CAR T cell generation. Oncotarget, 8(10), 17002.

29. Choi, B. D., Yu, X., Castano, A. P., Darr, H., Henderson, D. B., Bouffard, A. A., ... \& Maus, M. V. (2019). CRISPR-Cas9 disruption of PD-1 enhances activity of universal EGFRvIII CAR T cells in a preclinical model of human glioblastoma. Journal for Immunotherapy of cancer, 7(1), 1-8.

30. Ren, J., Liu, X., Fang, C., Jiang, S., June, C. H., \& Zhao, Y. (2017). Multiplex genome editing to generate universal CAR $\mathrm{T}$ cells resistant to PD1 inhibition. Clinical cancer research, 23(9), 2255-2266. 
31. Fourcade, J., Sun, Z., Pagliano, O., Guillaume, P., Luescher, I. F., Sander, C., ... \& Zarour, H. M. (2012). CD8+ T cells specific for tumor antigens can be rendered dysfunctional by the tumor microenvironment through upregulation of the inhibitory receptors BTLA and PD-1. Cancer research, 72(4), 887-896.

32. Qin, S., Xu, L., Yi, M., Yu, S., Wu, K., \& Luo, S. (2019). Novel immune checkpoint targets: moving beyond PD-1 and CTLA-4. Molecular cancer, 18(1), 1-14.

33. Shalem, O., Sanjana, N. E., Hartenian, E., Shi, X., Scott, D. A., Mikkelsen, T. S., ... \& Zhang, F. (2014). Genome-scale CRISPR-Cas9 knockout screening in human cells. Science, 343(6166), 84-87.

34. Rupp, L. J., Schumann, K., Roybal, K. T., Gate, R. E., Chun, J. Y., Lim, W. A., \& Marson, A. (2017). CRISPR/Cas9-mediated PD-1 disruption enhances anti-tumor efficacy of human chimeric antigen receptor T cells. Scientific reports, 7(1), 1-10.

35. Guo, X., Jiang, H., Shi, B., Zhou, M., Zhang, H., Shi, Z., ... \& Li, Z. (2018). Disruption of PD-1 enhanced the anti-tumor activity of chimeric antigen receptor $\mathrm{T}$ cells against hepatocellular carcinoma. Frontiers in pharmacology, 9, 1118

36. Nakazawa, T., Natsume, A., Nishimura, F., Morimoto, T., Matsuda, R., Nakamura, M., ... \& Nakase, H. (2020). Effect of CRISPR/Cas9-mediated PD-1-disrupted primary human third-generation CAR-T cells targeting EGFRvIII on in vitro human glioblastoma cell growth. Cells, 9(4), 998.

37. Zhang, Y., Zhang, X., Cheng, C., Mu, W., Liu, X., Li, N., ... \& Wang, H. (2017). CRISPR-Cas9 mediated LAG-3 disruption in CAR-T cells. Frontiers of medicine, 11(4), 554-562.

38. Sterner, R. M., Sakemura, R., Cox, M. J., Yang, N., Khadka, R. H., Forsman, C. L., ... \& Kenderian, S. S. (2019). GM-CSF inhibition reduces cytokine release syndrome and neuroinflammation but enhances CAR-T cell function in xenografts. Blood, The Journal of the American Society of Hematology, 133(7), 697-709.

39. Cooper, M. L., Choi, J., Staser, K., Ritchey, J. K., Devenport, J. M., Eckardt, K., ... \& DiPersio, J. F. (2018). An "off-the-shelf" fratricide-resistant CAR-T for the treatment of T cell hematologic malignancies. Leukemia, 32(9), 1970-1983.

40. Jung, I. Y., Kim, Y. Y., Yu, H. S., Lee, M., Kim, S., \& Lee, J. (2018). CRISPR/Cas9-mediated knockout of DGK improves antitumor activities of human T cells. Cancer research, 78(16), 4692-4703.

41. Tang, N., Cheng, C., Zhang, X., Qiao, M., Li, N., Mu, W., ... \& Wang, H. (2020). TGF- $\beta$ inhibition via CRISPR promotes the long-term efficacy of CAR T cells against solid tumors. JCI insight, 5(4). 
42. Zhang, W., Shi, L., Zhao, Z., Du, P., Ye, X., Li, D., ... \& Cai, J. (2019). Disruption of CTLA-4 expression on peripheral blood CD8+ $\mathrm{T}$ cell enhances anti-tumor efficacy in bladder cancer. Cancer chemotherapy and pharmacology, 83(5), 911-920.

43. Robbins, P. F., Morgan, R. A., Feldman, S. A., Yang, J. C., Sherry, R. M., Dudley, M. E., ... \& Rosenberg, S. A. (2011). Tumor regression in patients with metastatic synovial cell sarcoma and melanoma using genetically engineered lymphocytes reactive with NY-ESO-1. Journal of Clinical Oncology, 29(7), 917.

44. Chodon, T., Comin-Anduix, B., Chmielowski, B., Koya, R. C., Wu, Z., Auerbach, M., ... \& Ribas, A. (2014). Adoptive transfer of MART-1 T-cell receptor transgenic lymphocytes and dendritic cell vaccination in patients with metastatic melanoma. Clinical Cancer Research, 20(9), 2457-2465.

45. Mastaglio, S., Genovese, P., Magnani, Z., Ruggiero, E., Landoni, E., Camisa, B., ... \& Bonini, C. (2017). NY-ESO-1 TCR single edited stem and central memory T cells to treat multiple myeloma without graft-versus-host disease. Blood, The Journal of the American Society of Hematology, 130(5), 606-618.

46. Ahmadi, M., King, J. W., Xue, S. A., Voisine, C., Holler, A., Wright, G. P., ... \& Stauss, H. J. (2011). CD3 limits the efficacy of TCR gene therapy in vivo. Blood, The Journal of the American Society of Hematology, 118(13), 3528-3537.

47. Shao, H., Zhang, W., Hu, Q., Wu, F., Shen, H., \& Huang, S. (2010). TCR mispairing in genetically modified $\mathrm{T}$ cells was detected by fluorescence resonance energy transfer. Molecular biology reports, 37(8), 3951-3956.

48. Van Loenen, M. M., de Boer, R., Amir, A. L., Hagedoorn, R. S., Volbeda, G. L., Willemze, R., ... \& Heemskerk, M. H. (2010). Mixed T cell receptor dimers harbor potentially harmful neoreactivity. Proceedings of the National Academy of Sciences, 107(24), 10972-10977.

49. Aleksic, M., Liddy, N., Molloy, P. E., Pumphrey, N., Vuidepot, A., Chang, K. M., \& Jakobsen, B. K. (2012). Different affinity windows for virus and cancer-specific T-cell receptors: implications for therapeutic strategies. European journal of immunology, 42(12), 3174-3179.

50. Morgan, R. A., Dudley, M. E., Wunderlich, J. R., Hughes, M. S., Yang, J. C., Sherry, R. M., .. \& Rosenberg, S. A. (2006). Cancer regression in patients after transfer of genetically engineered lymphocytes. Science, 314(5796), 126-129.

51. Legut, M., Dolton, G., Mian, A. A., Ottmann, O. G., \& Sewell, A. K. (2018). CRISPR-mediated TCR replacement generates superior anticancer transgenic T cells. Blood, The Journal of the American Society of Hematology, 131(3), 311-322. 
52. Morton, L. T., Reijmers, R. M., Wouters, A. K., Kweekel, C., Remst, D. F., Pothast, C. R., ... \& Heemskerk, M. H. (2020). Simultaneous deletion of endogenous TCR $\alpha \beta$ for TCR gene therapy creates an improved and safe cellular therapeutic. Molecular Therapy, 28(1), 64-74.

53. Xue, S. A., Chen, Y., Voss, R. H., Kisan, V., Wang, B., Chen, K. K., ... \& Stauss, H. J. (2020). Enhancing the expression and function of an EBV-TCR on engineered T cells by combining Sc-TCR design with CRISPR editing to prevent mispairing. Cellular \& molecular immunology, 17(12), 1275-1277.

54. Stadtmauer, E. A., Fraietta, J. A., Davis, M. M., Cohen, A. D., Weber, K. L., Lancaster, E., ... \& June, C. H. (2020). CRISPR-engineered T cells in patients with refractory cancer. Science, 367(6481).

55. Zhao, L., \& Cao, Y. J. (2019). Engineered T cell therapy for cancer in the clinic. Frontiers in immunology, 10, 2250.

56. Abdelhakim, H., Abdel-Azim, H., \& Saad, A. (2017). Role of $\alpha \beta$ T cell depletion in prevention of graft versus host disease. Biomedicines, 5(3), 35.

57. Eyquem, J., Mansilla-Soto, J., Giavridis, T., van der Stegen, S. J., Hamieh, M., Cunanan, K. M., ... \& Sadelain, M. (2017). Targeting a CAR to the TRAC locus with CRISPR/Cas9 enhances tumour rejection. Nature, 543(7643), 113-117.

58. Georgiadis, C., Preece, R., Nickolay, L., Etuk, A., Petrova, A., Ladon, D., ... \& Qasim, W. (2018). Long terminal repeat CRISPR-CAR-coupled "universal" T cells mediate potent anti-leukemic effects. Molecular Therapy, 26(5), 1215-1227.

59. Fraietta, J. A., Nobles, C. L., Sammons, M. A., Lundh, S., Carty, S. A., Reich, T. J., ... \& Melenhorst, J. J. (2018). Disruption of TET2 promotes the therapeutic efficacy of CD19-targeted T cells. Nature, 558(7709), 307-312.

60. Bothmer, A., Gareau, K. W., Abdulkerim, H. S., Buquicchio, F., Cohen, L., Viswanathan, R., ... \& Cotta-Ramusino, C. (2020). Detection and modulation of DNA translocations during multi-gene genome editing in T cells. The CRISPR Journal, 3(3), 177-187.

61. MacLeod, D. T., Antony, J., Martin, A. J., Moser, R. J., Hekele, A., Wetzel, K. J., ... \& McCreedy, B. (2017). Integration of a CD19 CAR into the TCR alpha chain locus streamlines production of allogeneic gene-edited CAR T cells. Molecular Therapy, 25(4), 949-961.

62. Wiebking, V., Lee, C. M., Mostrel, N., Lahiri, P., Bak, R., Bao, G., ... \& Porteus, M. H. (2021). Genome editing of donor-derived $\mathrm{T}$ cells to generate allogeneic chimeric antigen receptor-modified T cells: optimizing $\alpha \beta$ T-cell-depleted haploidentical hematopoietic stem cell transplantation. Haematologica, 106(3), 847. 
63. Hale M, Lee B, Honaker Y, Leung W-H, Grier AE, Jacobs HM, et al. Homology-directed recombination for enhanced engineering of chimeric antigen receptor $\mathrm{T}$ cells. Mol Ther Methods Clin Dev. (2017) 4:192-203. doi: 10.1016/j.omtm.2016.12.008

64. Quazi, S. (2021). Vaccine in response to COVID-19: Recent developments, challenges, and a way out. Biomedical and Biotechnology Research Journal (BBRJ), 5(2), 105.

65. Quazi, S. (2021). Role of artificial intelligence and machine learning in bioinformatics: Drug discovery and drug repurposing.

66. Quazi, S., \& Jangi, R. (2021). Artificial intelligence and machine learning in medicinal chemistry and validation of emerging drug targets.

67. Namuduri, M., \& Brentjens, R. J. (2020). Enhancing CAR T cell efficacy: the next step toward a clinical revolution? Expert review of hematology, 13(5), 533-543. 